\title{
Pharmacist Knowledge \& Ability to Use Inhaled Medication Delivery Systems in UAE
}

\author{
Doaa Al Khalidi ${ }^{1}$, Amina Mahdy ${ }^{2}$, Nehal El kilany ${ }^{3}$, Farah Al Chikhoni ${ }^{4}$, \\ Fatima thabit ${ }^{5}$ and Saeed Khan ${ }^{6}$ \\ ${ }^{1}$ Corresponding author: Doaa Kamal Eddin Al Khalidi, MSc, Department of Clinical Pharmacy and Pharmacy \\ Practice, Dubai Pharmacy College, Dubai, United Arab Emirates, P.O Box 19099, Fax: +971 42646740 , \\ Telephone: +971 4 2120310; E-mail: \\ ${ }^{2}$ Department of Pharmacology and Toxicology, Dubai Pharmacy College, Dubai, United Arab Emirates . \\ ${ }^{3}$ Trainee Pharmacists \\ ${ }^{4}$ Department of Pharmaceutical Chemistry and Natural Product, Dubai Pharmacy College, Dubai, United Arab
} Emirates .

\begin{abstract}
:
Objective: This study was designed to compare knowledge \& ability to use different inhaling devices among both educated \& non-educated pharmacists.

Method: A questionnaire was constructed \& piloted to be used as a tool for this study. The sample was divided into two groups educated pharmacists \& non-educated pharmacists. Education was in term of receiving the brochures of demonstrating how to use the different inhaled devices before assessing the pharmacists. The pharmacists were asked to demonstrate usage of placebo devices \& assessment was done based on checklist designed following companies instructions.
\end{abstract}

Results: Statistics have shown significant $(P<0.05)$ higher scores; have been achieved by educated pharmacists when compared with non-educated pharmacists in term of ability to use the inhalers correctly, pharmacists' knowledge of cleaning MDI, inhalers induced mouth irritation side effect and their place of storage.

Conclusion: Pharmacists in UAE are not sufficiently aware of the steps to demonstrate correct use of different inhalers. The instructions supplied by the pharmaceutical companies are not sufficient. Appropriate and continuous educational programs concerning pharmacists' ability and knowledge of using different inhaled devices is recommended.

\section{INTRODUCTION}

Inhaled drugs have an important role in maintaining the control of the respiratory diseases 1,2 . The active ingredients of inhaled medications are delivered through different delivery systems 1, 3, like Metered dose inhalers, disc halers and turbuhalers. However, asthma related morbidity and costs still high despite the advanced management and treatment guidelines 4 , which may be due to many factors including the inappropriate technique of inhalation 4. Indeed, inhalation remains the main route of administration for asthma therapy, since it allows drugs to reach the target site with effective concentrations and low systemic bioavailability and consequently fewer side effects 5 . It has been revealed by some surveys that MDIs are frequently misused according to a review of 21 studies which found that the frequency of misusing MDIs ranges from 14-90\%, with an estimated average of 50\% 6,7. Another previous study found that improper usage of turbuhaler by medical personnel has lead to difficulty of using the device by patients which resulted in therapy failure 8,9,10.

Obviously, the patient cannot be expected to perform the proper use of different inhaler devices when health care professionals who have roles in patient education are unconfident and insufficient regarding the proper technique 3. However, it is patients' rights to be correctly educated in the self-administration of inhaled medication 3. Since dispensing pharmacists are the last health care providers that patients usually meet before attempting their medications, they have significant role in educating their patients regarding different inhaled medications and their devices 3.Therefore, this study has been designed to assess community pharmacists' knowledge and ability to use different types of inhaled medication devices in the UAE. 


\section{METHODS}

A questionnaire was constructed based on relevant studies in some countries other than UAE and piloted to be used as a tool for this study. It included general information like the way of pharmacist's advice offered for asthmatic patients regarding the proper use of inhaled medications, and whether it is the responsibility of pharmacists or other medical personnel to teach the patients. The questionnaire contained also pharmacists' knowledge related questions about use, storage and cleaning of different types of inhalers. Additionally, participating pharmacists were asked to demonstrate usage of placebo devices and assessment was done based on checklist designed following the pharmaceutical company instructions of each inhaled medication device as per the following table.

Table: Checklist items of demonstrating the use of MDI, turbuhaler and diskus.

\begin{tabular}{|c|c|c|}
\hline MDI & Turbuhaler & diskus \\
\hline $\begin{array}{ll}\text { - } & \text { Remove mouth piece cap } \\
\text { - } & \text { Shake the inhaler vigorously } \\
\text { - } & \text { Hold the inhaler upright } \\
\text { - } & \text { Keep head at level or slightly } \\
\text { tilted } \\
\text { - } & \text { Exhale gently but not fully } \\
\text { - } & \text { Insert mouth piece between } \\
\text { - } & \text { Beeth \& lips } \\
\text { - } & \text { Cou actuate canister once } \\
\text { - } & \text { Holnspinue slow and deep } \\
\text { - } & \text { Exhale slowly away from } \\
\text { - } & \text { piece } \\
\text { Replace cap }\end{array}$ & $\begin{array}{ll}\text { - } & \text { Remove cover } \\
\text { - } & \text { Hold the inhaler upright } \\
\text { horizontally } \\
\text { - } \\
\text { Turn bottom (right/clockwise) } \\
\text { then (left/anticlockwise) till } \\
\text { hear click } \\
\text { - } \quad \text { Exhale away from mouth piece } \\
\text { not fully } \\
\text { - } \quad \text { Place mouth piece between } \\
\text { your lips } \\
\text { Inhaling (breath) deeply \& } \\
\text { - } \quad \text { Horcefully } \\
\text { - } \quad \text { Exhale (from nose) away from } \\
\text { mouth piece } \\
\text { Replace cap and screw it shut }\end{array}$ & $\begin{array}{ll}\text { - } & \text { Open hygienic cover as far as } \\
\text { it will go (hear click) } \\
\text { - } & \text { Slide lever back as far as it will } \\
\text { go (to prime) } \\
\text { - } \quad \text { Exhale slowly away from } \\
\text { mouth piece } \\
\text { Place mouth piece between } \\
\text { your lips } \\
\text { - } \quad \text { Hold horizontally } \\
\text { - } \quad \text { Hold breath for 5-10 seconds } \\
\text { - } \quad \text { Exhale from nose slowly away } \\
\text { from mouth piece } \\
\text { - Close hygienic cover (no need } \\
\text { to return lever) }\end{array}$ \\
\hline
\end{tabular}

The period of this study was from November 2010 to February 2011. One hundred and twenty community \& clinic pharmacies in Abu-Dhabi, Dubai \& Al-Ain were randomly selected. In order to categorize the sample based on their previous education, pharmacists have been asked "Do companies provide you with instructions for the proper use of inhaler devices?" 50 pharmacists answered yes, 44 answered no, 5 were uncertain while 21 refused to participate. Thereafter, the sample was divided into two groups: 44 pharmacists (educated) \& 50 pharmacists (non-educated). Education was performed by handing out manufacturer's brochures along with brief explanation on the use of metered dose inhaler, turbuhaler and diskus.

After 2 weeks period, both pharmacists groups were assessed regarding knowledge \& ability to demonstrate proper use of the three aforementioned inhaler devices.

A relaxing interview atmosphere was established by emphasizing confidentiality of personal information \& eliminating possibility of being job-performance review.

Collected data were analyzed statistically using SPSS ${ }^{\circ}$ and a significance level of 0.05 was considered throughout.

\section{RESULTS}

A total of 94 of 120 pharmacists approved to participate in this study (response rate $=82.5 \%$ ). Generally, 50 pharmacists stated that they frequently receive medical representatives who provide instruction leaflets and/or demonstrations regarding the proper use of different inhaled devices, while 44 pharmacists confirmed they didn't receive as such. Fifty six percent $(56 \%)$ of participating pharmacists considered that it is pharmacist responsibility to teach patients how to use the inhaled devices correctly while $6 \%$ and $38 \%$ of them considered that its physicians and nurses roles respectively. Pharmacists strongly $(86 \%)$ favor demonstrating inhalers use to patients via models and devices. Ten percent used to explain orally the proper use and $4 \%$ mentioned they advise patients to read enclosed leaflets.

It has been found throughout the analysis of the ability to demonstrate inhalers (i.e. MDI, turbuhaler and diskus) use that educated pharmacists significantly $(\mathrm{P}<0.05)$ scored higher mean of correctly performed checklist steps than the non- educated pharmacists as shown in figure 1. 
Figure 1: Pharmacists ability to demonstrate use of inhalers correctly (Educated vs non-educated)

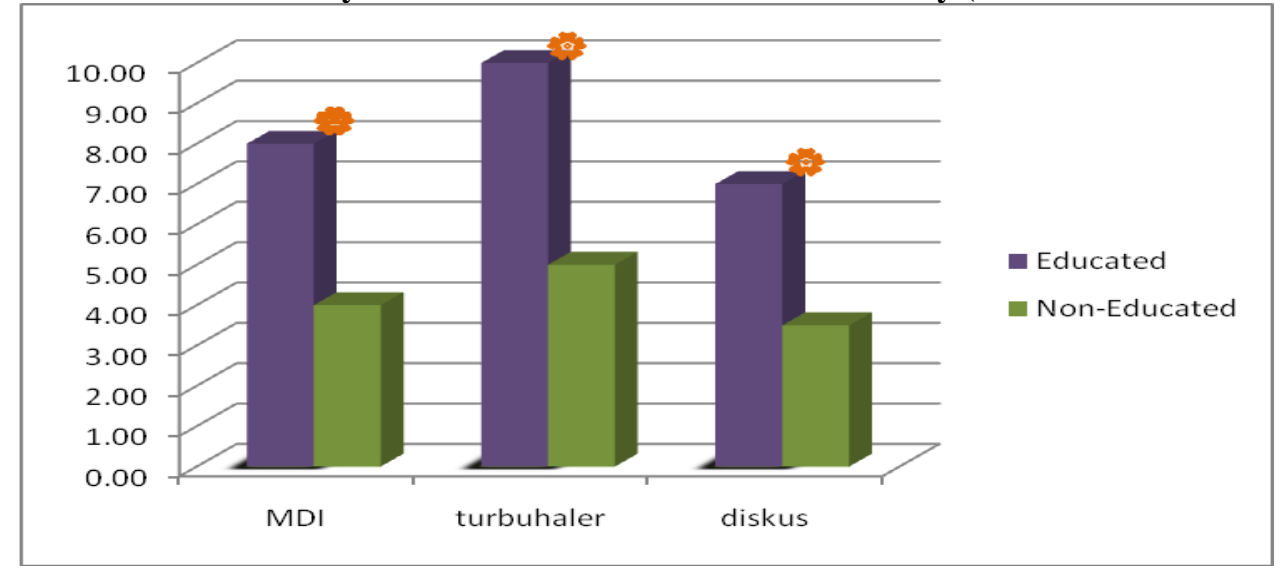

symbolizes presence of significant difference where $\mathbf{p}<0.05$

Concerning pharmacists' knowledge of the different inhaled devices, educated pharmacists have mentioned significantly $(\mathrm{P}<0.05)$ correct answers when compared with non-educated group regarding inhalers induced mouth irritation side effect and their place of storage as shown in figure 2.

Figure 2: Pharmacists Knowledge of inhalers re-administration, side effect and storage (educated vs noneducated)

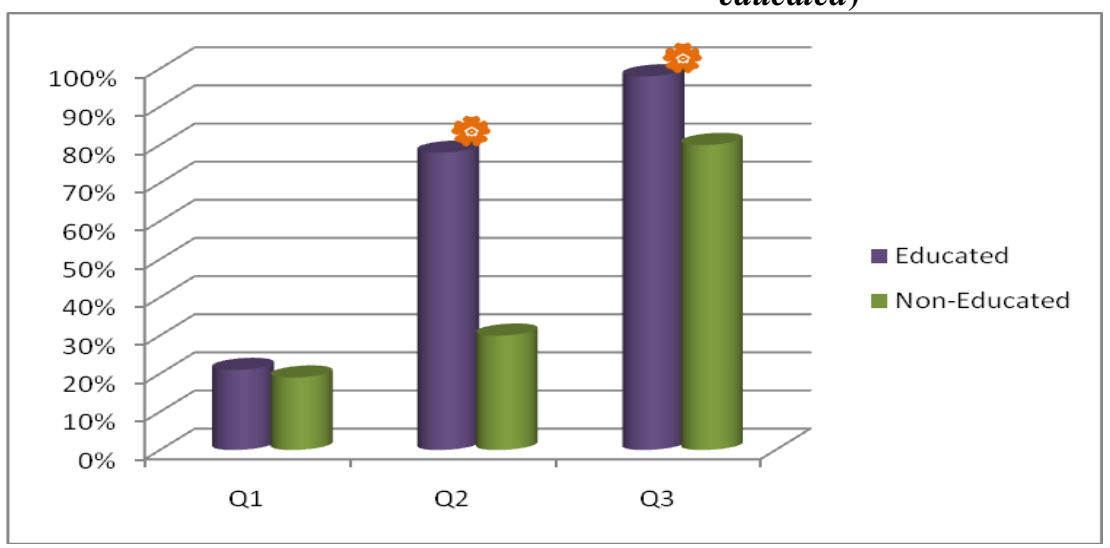

\begin{tabular}{|l|l|}
\hline No & Question \\
\hline Q1 & $\begin{array}{l}\text { How long to wait } \\
\text { between doses? }\end{array}$ \\
\hline Q2 & $\begin{array}{l}\text { How to prevent } \\
\text { irritation after use? }\end{array}$ \\
\hline Q3 & $\begin{array}{l}\text { What are ideal } \\
\text { storage conditions? }\end{array}$ \\
\hline
\end{tabular}

symbolizes presence of significant difference where $\mathrm{p}<0.05$

Moreover, pharmacists' knowledge of cleaning MDI analysis showed significant difference between educated and non-educated groups as shown in figure 3.

Figure 3: Pharmacists Knowledge of cleaning MDI (educated vs non-educated)

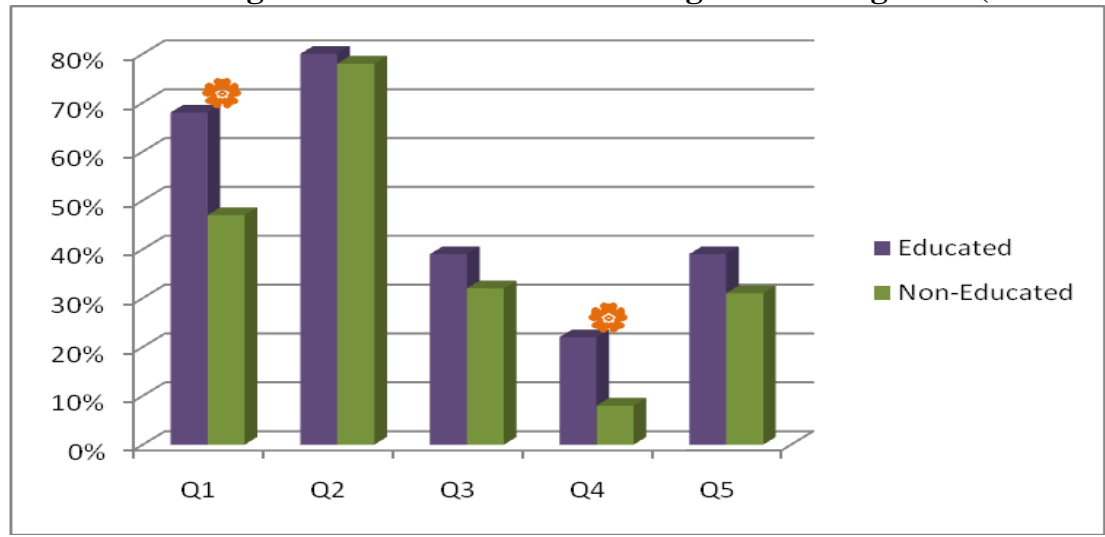

symbolizes presence of significant difference where $\mathrm{p}<0.05$

\begin{tabular}{|l|l|}
\hline No & Question \\
\hline Q1 & $\begin{array}{l}\text { Which part of } \\
\text { MDI is washed? }\end{array}$ \\
\hline Q2 & $\begin{array}{l}\text { With what is } \\
\text { MDI washed? }\end{array}$ \\
\hline Q3 & $\begin{array}{l}\text { How to dry MDI } \\
\text { device? }\end{array}$ \\
\hline Q4 & $\begin{array}{l}\text { If in hurry how } \\
\text { to dry MDI? }\end{array}$ \\
\hline Q5 & $\begin{array}{l}\text { Cleaning } \\
\text { Turbuhaler \& } \\
\text { Diskus? }\end{array}$ \\
\hline
\end{tabular}




\section{DISCUSSION}

Little studies have evaluated pharmacists' knowledge of and ability to use different inhaled medications in the UAE. The pharmacist is the last health care provider the patients meet before receiving their medications. Moreover, pharmacist should have a responsibility upon medication dispensing, as does the prescribing physician, to ensure that patients use prescribed drugs correctly 3. No matter how efficient the medication in MDI may be, poor inhaler technique may cause to be ineffective 11 and consequently all the other inhaled devices. Mainly, uncontrolled asthmatic patients can be simply identified by the pharmacists due to poor inhalation technique 12,13. Pharmacists as part of health care team must train their patients for the correct use of inhaled medications. Therefore, pharmacists should be able to practice the different inhalation techniques accurately in order to train their patients properly 14. As the concept of pharmaceutical care has been evolving and had encouraged involvement of pharmacists in patient care process 15, pharmacists should recognize the ethical responsibilities toward their patients 16. Proper patients counseling and education of their medications is one of them. In our study we focused on community pharmacists as in the current practice they are in the business of selling medicines 16 and have a major role in counseling patients about the appropriate use and storage of drugs 17 including inhaled devices, while failure to achieve that can result in ineffective medications that may adversely affect the health and safety of patients 16 . Our study identified important tips that should be offered by pharmacists through patient education and counseling sessions, where the participants found to be less knowledgeable regarding these issues. Examples of these tips are the appropriate way to prevent mouth irritation after using inhalers, the ideal storage conditions, washing and drying MDIs. This is complied with other studies which reported pharmacist's deficient knowledge in educating the patient about the proper use of inhalers 18,19. It is perhaps surprising that most of participating pharmacists strongly favor demonstrating inhalers use to patients via models and devices. This found to be in contrast to a study revealed pharmacists often had difficulty demonstrating correct usage of inhaling devices; saying that teaching physical tasks with apparatus is outside the pattern of practice for pharmacists whose educational role is usually perceived as written or verbal advice 3. Additionally, it was noticed that non-educated group of participants demonstrate a poor knowledge and performance of using different inhalers compared to the educated group. This finding agreed by a study which was conducted in Saudi Arabia in 2012 in which community pharmacists display a weak practice toward the proper steps of using inhalers20. Finally, there is a high probability of dispensing inhaled medications by community pharmacists without prescriptions. Therefore, pharmaceutical representatives have major role in enhancing community pharmacists' awareness and skills of using such type of drug delivery systems. Additionally, it has been noticed by a study that knowledge about the inhaler technique may be declined if not reviewed on a routine basis 21 .

\section{CONCLUSION}

We conclude that pharmacists in UAE are not sufficiently aware of the steps to demonstrate correct use of different inhalers. However, they strongly favor demonstrating inhalers use for the patients taking in consideration that it is one of their main professional tasks in the community pharmacy practice setting. Relying on the instructions supplied by the different companies is not sufficient for pharmacist education regarding the proper use of these devices. Therefore, it is recommended to encourage and initiate appropriate and continuous educational programs for pharmacists regarding the proper use of different inhaler devices, as stated in international guidelines of asthma in order to contribute for successful therapy of respiratory diseases.

\section{ACKNOWLEDGEMENT:}

The authors would like to express gratitude to all the participating pharmacists. They also thank AstraZeneca \& GlaxoSmithKline for their help by supplying the needed devices. The authors are grateful to Dr. Marwa Khalil, Lecturer of Public Health, Community Medicine Department, Faculty of Pharmacy, Zagazig University, Egypt for performing the statistical analysis of the data.

\section{References}

[1]. Palen et al. Evaluation of long term effectiveness of three instruction modes for inhaling medicines. Patient Education and Counseling 32 (1997) S87-S95.

[2]. E. Mehuys, L. Van Bortel, L. De Bolle, I. Van Tongelen, L. Annemans, J.P. Remon and G. Brusselle. Effectiveness of pharmacist intervention for asthma control improvement. Eur Respir J 2008; 31: 790-799

[3]. Steven Kesten, M.D., F.C.C.P; Kevin Zive; and Kenneth R. Chapman, M.D., F.C.C.R. Pharmacist Knowledge and Ability to Use Inhaled Medication Delivery Systems. Chest 1993;104;1737-1742

[4]. V. Giraud, N. Roche. Misuse of corticosteroid metered-dose inhaler is associated with decreased asthma stability. Eur Respir J 2002; 19: 246-251

[5]. Roche N, Chinet T, Huchon G. Ambulatory inhalation therapy in obstructive lung diseases. Respiration 1997; 64: 121-130.

[6]. Chinet T, Huchon G. Misuse of pressurized metered dose aerosols in the treatment of bronchial diseases. Incidence and clinical consequences. Ann Med Interne 1994; 145: 119-124. 
[7]. Hanania NA, Wittman R, Kesten S, Chapman KR. Medical personnel9s knowledge of and ability to use inhaling devices. Metereddose inhalers, spacing chambers, and breath-actuated dry powder inhalers. Chest 1994; 105: 111-116.

[8]. Nicola A. Hanania, M.D.; Richard Wittman; Steven Kesten, M.D., and Kenneth R. Chapman, M.D. Medical Personnel's Knowledge of and Ability to Use Inhaling Devices Metered-Dose Inhalers, Spacing Chambers, and Breath-actuated Dry Powder Inhalers. Chest 1994; 105; 111-116

[9]. Newman SP. Aerosol deposition considerations in inhalation therapy. Chest 1985; 88:152S-160S.

[10]. Human B. Aerosol deposition and delivery of therapeutic aerosols. J Asthma 1991; 28:239-42

[11]. Lindgren S, Bake B, Larsson S. Clinical consequences of inadequate inhalation technique in asthma therapy. Eur J Respir Dis 1987;70:93-8.

[12]. Ekedahl, A., 1996. 'Open-ended questions' and 'show-and-tell' - a way to improve pharmacist counselling and patients handling of their medicines. J. Clin. Pharm. Ther. 21 (2), 95-99.

[13]. Cordina, M., McElnay, J.C., 2001. Assessment of a community pharmacy-based program for patients with asthma. Pharmacother.: J. Human Pharmacol. Drug Ther. 21 (10), 1196-1203.

[14]. M Lee-Wong, P H Mayo. Results of a programme to improve house staff use of metered dose inhalers and spacers. Postgrad Med J 2003;79:221-225

[15]. Bond C, Matheson C, Williams S, Williams P, Donnan P. Repeat prescribing: a role for community pharmacists in controlling and monitoring repeat prescriptions. Br J Gen Pract. 2000;50(453): 271-5.

[16]. Resnik DB, Ranelli PL, Resnik SP. The conflict between ethics and business in community pharmacy: what about patient counseling? J Bus Ethics. 2000;28(2):179-86.

[17]. Ballantyne, P.J., 2007. The role of pharmacists in primary care. BMJ 334 (7603), 1066-1067.

[18]. Chopra, N., Oprescu, N., et al., 2002. Does introduction of new "easy to use'" inhalational devices improve medical personnel's knowledge of their proper use? Ann. Allergy, Asthma \& Immunology 88 (4), 395-400.

[19]. Basheti, I.A., Reddel, H.K., et al., 2005. Counseling about turbuhaler technique: needs assessment and effective strategies for community pharmacists. Respir. Care 50 (5), 617-623.

[20]. Tahir Mehmood Khan, Saira Azhar. A study investigating the community pharmacist knowledge about the appropriate use of inhaler, Eastern Region AlAhsa, Saudi Arabia. Saudi Pharmaceutical Journal (2013) 21, 153-157.

[21]. Skaer, T., Wilson, C., et al., 1996. Metered-dose inhaler technique and quality of life with airways disease: assessing the value of the Vitalograph in educational intervention. J. Int. Med. Res. 24 (4), 369-375. 